\title{
Studies on the interaction of the carbohydrate binding module 3 from the Clostridium thermocellum CipA scaffolding protein with cellulose and paper fibres
}

\author{
João Machado $\cdot$ Adriano Araújo · Ricardo Pinto · \\ Francisco M. Gama
}

Received: 1 August 2008/Accepted: 3 April 2009/Published online: 23 April 2009

(C) Springer Science+Business Media B.V. 2009

\begin{abstract}
The adsorption of a carbohydrate binding module (CBM3) from the Clostridium thermocellum scaffolding protein (CipA) to cellulose was analysed in this work. The effect of CBM-PEG on the drainability of E. globulus and $P$. sylvestris pulps and on the physical properties of the respective papersheets was also studied. The CBM binding to cellulose is often described as "irreversible", but this classification does not fully characterize this interaction. Indeed, the results obtained demonstrate that, although the adsorption on cellulose is rather stable, CBM inter-fibre mobility may be observed. The results also showed that the CBM-PEG conjugate improves the drainability of $E$. globulus and $P$. sylvestris pulps without affecting the physical properties of the papersheets.
\end{abstract}

Keywords Cellulose - CBM3 - Clostridium thermocellum · Adsorption · Pulp drainability

\section{Introduction}

The interaction of CBMs with cellulose has been characterized as irreversible; other studies, though,

J. Machado · A. Araújo · R. Pinto · F. M. Gama ( $\bowtie)$ IBB, Institute for Biotechnology and Bioengineering, Centre of Biological Engineering, Universidade do Minho, Campus de Gualtar, 4710-057 Braga, Portugal e-mail: fmgama@deb.uminho.pt describe it as a dynamic process. Indeed, studies using fluorescent labelled CBMs showed that these proteins exhibit surface mobility on crystalline cellulose (Jervis et al. 1997). The "irreversible" nature of this interaction, that depends both on the CBM and cellulose properties, is not fully characterized. Cellulose presents multiple overlapped binding sites and even in model substrates the surface is heterogeneous. It is generally accepted that the adsorption is ruled by multiple reversible interactions between the glucose molecules and the CBM. Thus, desorption requires multiple interactions to break simultaneously (Shoseyov and Warren 1997).

It has been shown that the treatment of cellulose fibres with CBMs alters the interfacial properties of the fibres (reviewed by Shoseyov et al. 2006). These properties-tight adsorption and potential to modify the surface properties - contribute to the utilization of CBMs in different fields of biotechnology; one of these fields is the paper industry, which has tradition in the utilization of proteins, in particular enzymes (Suurnäki et al. 1994; Senior and Hamilton 1993; Geng and Li 2003; Seo et al. 2000; Jackson et al. 1993; Pala et al. 2001). Indeed, it has been shown that CBMs, obtained by proteolysis of Trichoderma reesei cellulases, are capable of modifying the drainability of recycled paper pulps (Pinto et al. 2004). Conjugates of CBMs (Kitaoka and Tanaka 2001) and fusion proteins with several CBMs (for instance, fused starch and cellulose binding modules; Levy et al. 2002) has also been shown to improve the mechanical 
properties of papersheets (Levy et al. 2002). Furthermore, CBMs were also successfully used for the depilling of cotton fabrics (Ramos et al. 2007). Thus, there is considerable evidence that CBMs may be used for the modification of the technical properties of cellulosic materials. A deeper characterization of the interaction CBM-cellulose will help the development of the CBM-based technologies.

In the present work, we analyse the CBM adsorption reversibility and mobility, and the effect of a CBM-PEG conjugate in the properties of E. globulus and $P$. sylvestris pulps and papersheets. Since PEG is highly hydrophilic, its conjugation with CBM followed by the adsorption of CBM-PEG in the fibres is expected to modify the surface wetability. Furthermore, the comparison of the technical properties of pulps and paper fibres treated with CBM and CBMPEG may reveal the effect of the surface hydration on those properties. The CBMs from Clostridium thermocellum have been described in previous studies (Najmudin et al. 2005; Fontes et al. 1995, 2004; Xie et al. 2001), and were selected in this work.

\section{Materials and methods}

Chemicals

Sodium acetate trihydrate was obtained from AppliChem (Darmstadt, Germany), O-[2-(3-Mercaptopropionylamino)ethyl]- $\quad \mathrm{O}^{\prime}$-methyl-PEG 5,000 was purchased for Sigma (St. Louis, Mo.). Paper fibres were kindly supplied by Prof. Ana Paula Duarte, from the University of Beira Interior.

\section{Protein production}

Clostridium thermocellum was used as source of genomic DNA. The bacterium was grown anaerobically under a nitrogen atmosphere at $60{ }^{\circ} \mathrm{C}$, in a prereduced medium with $1 \%(\mathrm{w} / \mathrm{v})$ cellobiose. The carbohydrate binding module (CBM3) from the Clostridium thermocellum scaffolding protein (CipA) coding sequence was amplified by PCR, cloned in the expression vector pET21a and produced as described in previous works (Klyosov and Sinitsyn 1981; Kataeva et al. 1999, 2001). The CBM3 construct includes a linker, a peptide that links the CBM to other modules in the scaffolding CipA protein. The
Table 1 Peptide sequence of CBM3

\begin{tabular}{ll}
\hline Protein & Peptide sequence \\
\hline CBM3 & TPTKGATPTNTATPTKSATATPTRPSVPTNTP \\
\cline { 2 - 2 } & TNTPANTPVSGNLKVEFYNSNPSDTTNSIN \\
& PQFKVTNTGSSAIDLSKLTLRYYYTVDGQ \\
& KDQTFWCDHAAIIGSNGSYNGITSNVKGT \\
& FVKMSSSTNNADTYLEISFTGGTLEPGAHV \\
& QIQGRFAKNDWSNYTQSNDYSFKSASQFV \\
& EWDQVTAYLNGVLVWGKEHHHHHH \\
\hline
\end{tabular}

The linker sequence is underlined

full sequence of the protein produced in this work, including the CBM3 and the linker, is shown in Table 1.

Adsorption reversibility assays

Suspensions of Whatman CF11 fibres, with concentration of $80 \mathrm{mg} / \mathrm{mL}$, were incubated for $2 \mathrm{~h}$ at $4{ }^{\circ} \mathrm{C}$, in the presence of a $\mathrm{CBM} 3$ at a concentration of $0.73 \mathrm{mg} / \mathrm{mL}$. The fibers were then centrifuged at $4,000 \mathrm{rpm}$ for $10 \mathrm{~min}$. The supernatant was discarded, and the pellet washed twice with the CBM buffer solution (Tris $20 \mathrm{mM}, \mathrm{NaCl} 20 \mathrm{mM}, 5 \mathrm{mM}$ $\left.\mathrm{CaCl}_{2}\left(2 \mathrm{H}_{2} \mathrm{O}\right), \mathrm{pH}=7.0\right)$ and $5 \mathrm{mM}$ of phenylmethanesulphonylfluoride (PMSF). The fibres were resuspended in different solutions $(1 \mathrm{~mL})$, in order to analyse the stability of the CBM3 adsorption. The following conditions were used: urea $0.5 \mathrm{M}$, urea $1 \mathrm{M}$, Glucose $1 \mathrm{M}$, pH 5 buffer (glycin $0.1 \mathrm{M}$ ), pH 3 buffer (glycin $0.1 \mathrm{M}$ ), pH 7 buffer $(100 \mathrm{~mL}$ of $\mathrm{KH}_{2} \mathrm{PO}_{4} \quad 0.1 \mathrm{M}$ and $58.2 \mathrm{~mL}$ of $\mathrm{NaOH} 0.1 \mathrm{M}$ ), pH11 buffer (100 mL of $\mathrm{Na}_{2} \mathrm{HPO}_{4} 0.05$ and $8.2 \mathrm{~mL}$ of $\mathrm{NaOH} 0.1 \mathrm{M}), \mathrm{pH} 13$ buffer $(50 \mathrm{~mL}$ of $\mathrm{KCl} 0.2 \mathrm{M}$ and $132 \mathrm{~mL}$ of $\mathrm{NaOH} 0.2 \mathrm{M}$ ), ultrapure water, $\mathrm{NaCl}$ $0.5 \mathrm{M}$, ethylene glycol and SDS, both at $1 \%$ concentration. The mixtures were allowed to interact for $2 \mathrm{~h}$ at room temperature, with gentle stirring. Then, the fibres were centrifuged and the supernatants analysed by SDS-PAGE electrophoresis.

\section{Mobility assays}

These assays were carried out using fluorophores conjugates of the CBM. The CBM3 conjugation with FITC (florescein isotiocyanate) and TRITC (tetramethylrodamine), was made using a ratio of $1: 3$ (protein: fluorochrome). The fluorochrome was 
dissolved in DMSO (2\% of the protein volume), and allowed to react with the protein overnight, at room temperature and with slow stirring.

After conjugation, the protein was purified using a PD-10 column. The conjugated CBMs were allowed to adsorb on Whatman fibers CF $11(30 \mathrm{mg})$, for $2 \mathrm{~h}$. The fibers were centrifuged ( $5 \mathrm{~min}, 12,000 \mathrm{rpm}$ ) and washed with buffer. Fibres with CBM linked to each fluorophore were separately prepared. Then, the two samples were mixed $(0.5 \mathrm{~mL}$ for each sample), and allowed to interact.

The mixture was kept in suspension by magnetic stirring, at $5{ }^{\circ} \mathrm{C}$. Samples were collected immediately after mixing the fibres, and after 1, 2, 5, and 8 days.

Fluorescence microscopy observations were performed in a Zeiss Axioskop microscope (Zeiss, Oberkochen, Germany) equipped with a Zeiss Axiocam HRc attached camera (Zeiss, Oberkochen, Germany) and using the Axiovision 3.1 software (Zeiss, Oberkochen, Germany).

The fibres with CBM-FITC were detected using a filter with blue excitation (BP excitation 450-490, Dichrioc FT 510; emission LP 515), and the protein stained with TRITC was observed using a green excitation filter (BP excitation 546/12, Dichroic FT 580; emission LP 590).

Quantification of cellulose adsorption by image analysis

The proteins were conjugated with FITC, and then the CBM3 was purified in a PD-10 column, previously equilibrated with an appropriate buffer (Tris $20 \mathrm{mM}, \quad \mathrm{NaCl} 20 \mathrm{mM}, \quad 5 \mathrm{mM} \quad \mathrm{CaCl}_{2}\left(2 \mathrm{H}_{2} \mathrm{O}\right)$, $\mathrm{pH}=7.0$ ). The absorbance of the sample containing CBM3 was read at 280 and $495 \mathrm{~nm}$.

A sample of CBM3 (1 mL), with concentrations of 50 and $500 \mu \mathrm{g} / \mathrm{mL}$, was added to $20 \mathrm{mg}$ of Whatman $\mathrm{CF} 11$, and lefted stirring for $2 \mathrm{~h}$ at $4{ }^{\circ} \mathrm{C}$. The mixture was centrifuged at $12,000 \mathrm{rpm}$ for $5 \mathrm{~min}$, and the supernatant was discarded.

Fluorescence microscopy observations of the fibres were performed using the equipments described in the previous section, using the blue excitation filter.

The surface concentration of CBD-FITC conjugates, adsorbed on cellulose fibers, was determined by image analysis. The program used for this calculation consists of two scripts, the first dedicated to the elaboration of the calibration curve. The emission of fluorescent light, detected by image analysis, is correlated with the concentration of CBDs. This calibration is then used (second script) to determine the concentration of CBDs adsorbed on cellulosic fibers. This method allows the direct estimation of the adsorbed CBDs surface concentration, which usually is not accurately calculated from depletion studies since the surface area is hardly known. The methodology used is described elsewhere in detail (Pinto et al. 2007, 2008).

The calibration curve for different times of acquisition was obtained using protein (CBM-FITC) solutions with different concentrations $(0,15,20,25$, $30,35,40,45,50,60,70,80,90,100,110,120,135$ and $150 \mu \mathrm{g} / \mathrm{mL}$ ). The images were taken with Axiskop microscope with the blue excitation filter. The quantification of the CBM3 adsorbed to the CF11 fibres was performed using the script of the MATLAB $^{\circledR}$ (The Mathworks, Inc.; EUA), developed by (Pinto et al. 2007, 2008).

\section{CBD-PEG conjugation}

The conjugates CBM-PEG were prepared with the purpose of mimetizing the glycosidic fraction in fungal CBMs, and to analyse the effect of surface hydration on the technical properties of paper fibres.

The PEG (O-[2-(3-Mercaptopropionylamino) ethyl]$\mathrm{O}^{\prime}$-methyl-PEG, $\left.\mathrm{Mw}=5,000\right)$ was added to the protein solution with magnetic stirring and allowed to react overnight at $4{ }^{\circ} \mathrm{C}$ (Abushowski et al. 1977; Bailon and Berthold 1998). A molar ratio of 3\% (PEG:CBM3 amino groups) was used. As shown elsewhere, in these conditions, the modified CBM3 still binds to the fibres (Data not shown).

Treatment of E. globulus and P. sylvestris fibres with CBM3 and CBM3-PEG conjugate

Paper fibres were refined (3,000 revolutions) in a PFI mill. The CBM3 and CBM3-PEG conjugate were allowed to adsorb on the refined fibres by mixing the protein at a concentration of $1 \mathrm{mg}$ per gram of fibre (dry weight), using $15 \mathrm{~g}$ of fibers (dry weight) in acetate buffer $(50 \mathrm{mM}, \mathrm{pH} 5.0$, final volume of $600 \mathrm{~mL}$ ), for $30 \mathrm{~min}$ at room temperature. 
Analysis of the pulp and paper properties

The pulp and handsheet properties were analysed using standard procedures: ISO 5267/1 (ShopperRiegler); ISO 5636/3 1992 (F) (permeability); ISO 1924/2 1985 (F) (tensile strength and break length); ISO 1947 (F) (tearing); ISO 27581983 (F) (bursting strength).

\section{Results and discussion}

Production and purification of the proteins

The SDS-PAGE analysis (Fig. 1) shows that the obtained CBM3 is highly pure and exhibits an apparent molecular weight according to the theoretical value of 22,112 Da.

\section{Adsorption reversibility studies}

The stability of the CBM adsorption on cellulose fibres was analysed incubating the fibres with adsorbed protein in solutions with different $\mathrm{pH}$, ionic strength, and with different additives. The desorbed protein, separated from the fibres by centrifugation, was analysed by silver stained SDS-PAGE.

The gel (Fig. 2) reveal that, for all of the studied conditions, CBM3 desorption occur to different

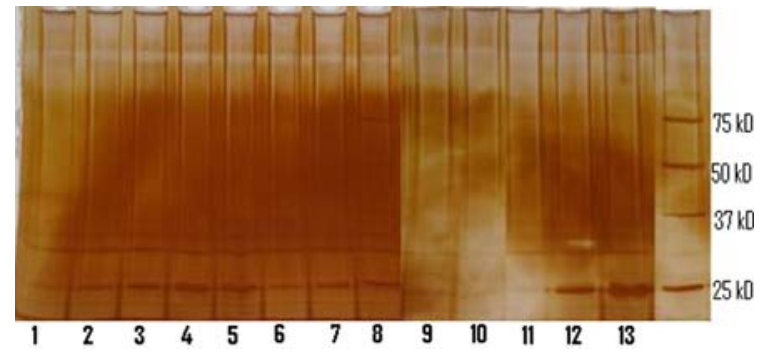

Fig. 2 SDS-PAGE analysis of CBM3 desorbed using different solutions: 1: Urea $0.5 \mathrm{M}$; 2: Urea $1 \mathrm{M}$; 3: Glucose $1 \mathrm{M}$; 4 : $\mathrm{pH} 2 ; 5: \mathrm{pH} 3 ; 6: \mathrm{pH}$ 7; 7: $\mathrm{pH}$ 11; 8: $\mathrm{pH} \mathrm{13;} \mathrm{9:} \mathrm{Ultrapure} \mathrm{water;}$ 10: $\mathrm{NaCl} 0.5 \mathrm{M}$; 11: Ethyleneglycol; 12: SDS 1\%, 13: Initial amount of protein used in the assay

extents, although in most cases only tiny amounts of protein is released. It must be remarked that the gel is silver stained, and therefore very low amounts of protein are being detected. As a matter of fact, when the gel is stained with Coomassie Blue, only solutions with low $\mathrm{pH}$ or SDS releases detectable amounts of CBM off the fibres (data not shown).

These results confirm the data from previous studies, suggesting that the adsorption of CBM3 is quite stable (Shoseyov and Warren 1997). However, it is demonstrated that the adsorption may not be considered irreversible. To further characterize the reversible/irreversible character of the interaction, a mobility assay was carried out using CBMs conjugated with fluorochromic labels.
Fig. 1 SDS-PAGE electrophoresis, evaluation of the production and purification of the CBM3 in the His-tag column. 1: Protein extract; 2: Flow fraction; 3, 4, 5: 2nd wash; 6: Imidazol $300 \mathrm{mM}$ elution; 7: Imidazol $500 \mathrm{mM}$ elution; 8 : Purification (PD-10); 9: Protein marker

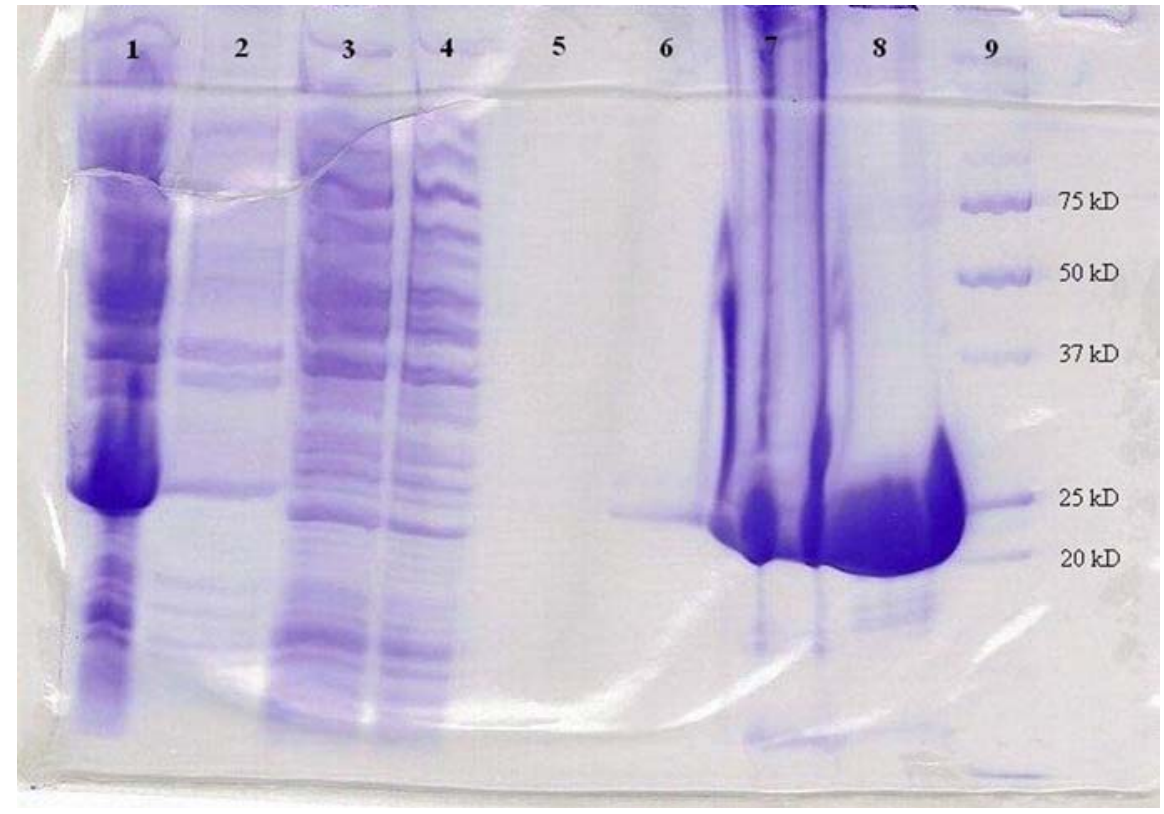


Mobility assays

According to the results shown in the previous section, the CBM3 is reversibly bound cellulose. The microscopic observation of fibres with labelled CBMs, using the appropriate filters, allows the characterization of the surface mobility/adsorption reversibility. This assay provides a way to directly observe whether CBMs, once adsorbed to cellulose, are able to move to other fibres in a cellulose suspension. In this assay, CBMs are labelled with different fluorochromes, FITC and TRITC. Then, the labelled CBMs are mixed with the fibres, separately. Finally, the two fibre samples are mixed and the mobility of CBMs among fibres is detected by a colour change of the fibres. If, after mixture of the fibres, they gradually become indistinct on the fluorescence microscope, this implies that CBM-FITC and CBM-TRITC are able to move from one fibre to another, until the fibre "colour" becomes homogeneous.

As can seen in the Fig. 3, there is a clear difference, immediately after mixture, in the colour exhibited by the fibres with adsorbed protein stained either with FITC or TRITC, which allows their differentiation. As a matter of fact, each fibre can be observed using only one of the filters. Thus, each fibre bears adsorbed CBMs with only one of the fluorochromes used.

The following sample observed was collected $24 \mathrm{~h}$ after mixing the fibres. It is possible to observe that, despite the existence of some fibres that are much
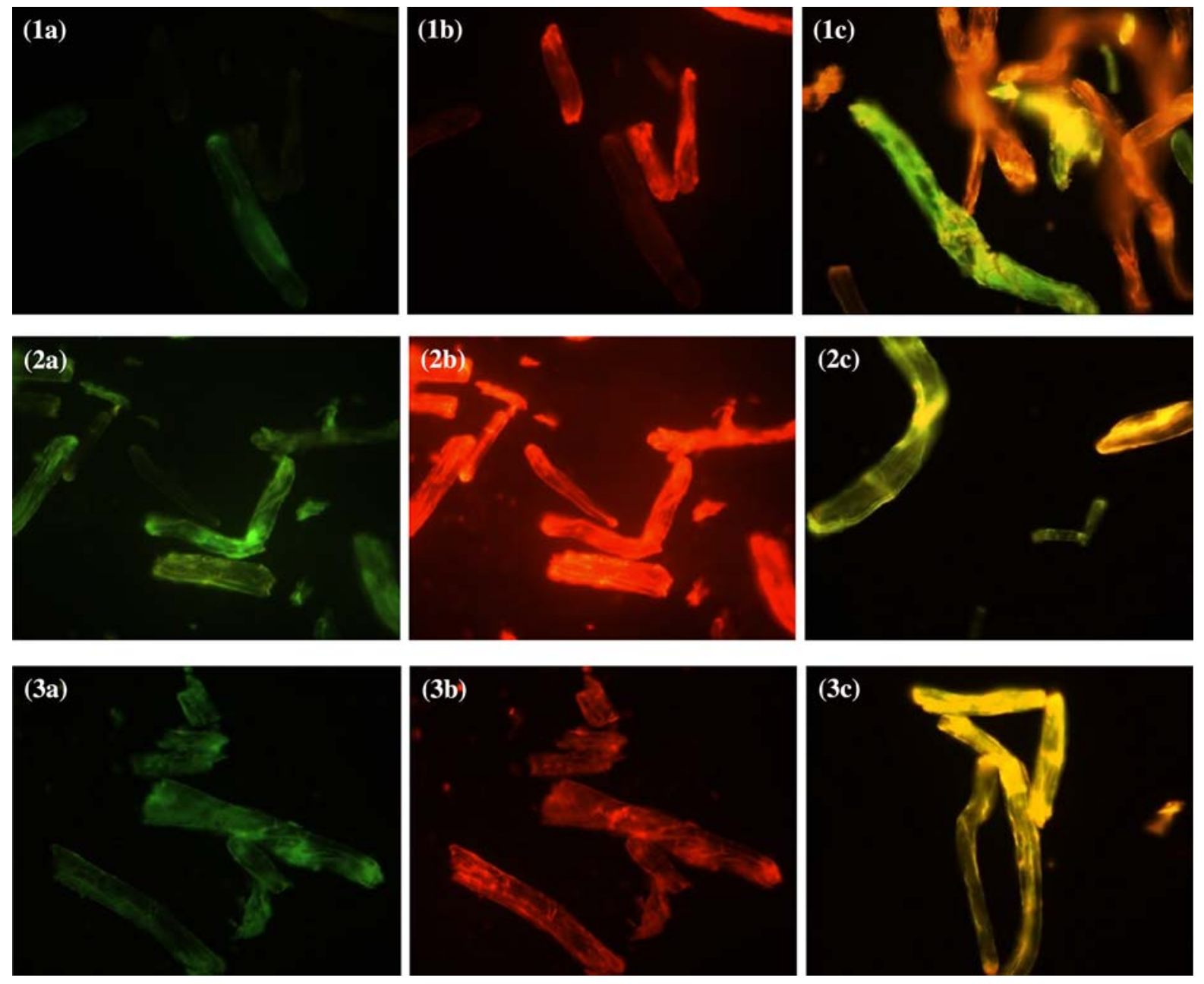

Fig. 3 (1) Selected image for the contact time of $0 \mathrm{~h}$. (2) Selected image for the contact time of $24 \mathrm{~h}$. (3) Selected image for the contact time of $192 \mathrm{~h}$. The same observation field, in the microscope, was photographed using different filters, a FITC filter, b TRITC filter and-in this case a different field is shown-c overlapped images of both filters 
better noticed using one of the filters, there are some fibres that may be observed using either filter. These results suggest that, after $24 \mathrm{~h}$, the mobility of the CBMs between fibres occurred already to some extent.

After 8 days of contact, it is no longer possible to recognize the kind of proteins (with FITC or TRITC) originally adsorbed on each fibre. Similar results were obtained after 48 and $70 \mathrm{~h}$ (not shown), demonstrating the inter-fibre mobility of the protein. So, despite the results suggesting that the adsorption is irreversible, due to the difficulty in removing the protein from the fibres using different solutions (previous section), a gradual transfer between fibres occur, and so we can conclude that the adsorption is reversible.

Thus, it is possible to conclude that, after several days, CBM3 moves from one fibre to another. This result is in agreement with studies that showed that $\mathrm{CBM}_{\mathrm{Cex}}$ is mobile on the surface of crystalline cellulose (Jervis et al. 1997), and with authors claiming that the mobility of CBMs may explain the function of CBMs (Shoseyov et al. 2006).

Quantification of protein surface concentration

The surface concentration of CBMs was estimated using an image analysis methodology, as referred in the materials and methods section. Basically, a correlation between the fluorescent intensity and the signal recorded in a digital camera is obtained using solutions of CBM-FITC with known protein concentration. Then, the signal obtained in the analysis of fibres with adsorbed CBD-FITC is related to the surface concentration using this calibration. In average, a surface concentration of 40.60 and $83.30 \mu \mathrm{g} / \mathrm{mL}$ was obtained for fibres equilibrated with CBM3 solutions with concentration of 50 and $500 \mu \mathrm{g} / \mathrm{mL}$. The number of adsorbed CBM layers was calculated using the MATLAB program (for more detail on the calculations please see references Pinto et al. 2007, 2008); the estimated number of adsorbed CBM layers was 0.8 and 1.5, respectively, for the lower and higher CBM concentration used. These results are similar to the ones obtained previously, using a CBM from $T$. reesei, and show that a high surface concentration exists at saturation, as expected, roughly corresponding to a protein monolayer covering the fibres. This is in our view a relevant finding: the effect of CBMs on the technical properties of cellulosic fibres can be assigned to the modification of interfacial properties, only if a high surface coverage is achieved, as seems to be the case.

CBM and CBM-PEG treatment of E. globulus and $P$. sylvestris fibres

In previous work (Pinto et al. 2004; Ramos et al. 2007), we showed that fungal CBMs, heavily glycosylated, modify the properties of textiles and paper pulps. This effect may be assigned, theoretically, either to the modification of interfacial properties or to the disruption of the fibres. In this work, a CBM expressed in bacteria (not glycosylated) was tested in the treatment of paper fibres. Although both CBMs (the fungal used in previous studies, and the bacterial produced in this work) have high affinity for cellulose, they would be expected to introduce different surface properties to the fibres were they adsorb, since glycosylation is lacking in the bacterial protein. To confirm this hypothesis, and check the relevance of the glycosylation in this regard, the CBM3 was modified by pegylation - an attempt to mimetize the glycosidic fraction present in fungal bacteria which, as PEG, is likely to be highly hydrated.

The goal of this part of the study was to analyse the effect of CBM3 on the pulp and paper properties, specifically to check whether the protein adsorption introduce significant changes in fibre properties. Previous works have shown that CBM-PEG is capable of modifying the drainability of recycled paper pulps without changing negatively the physical properties. The pulp drainability is the capacity of the

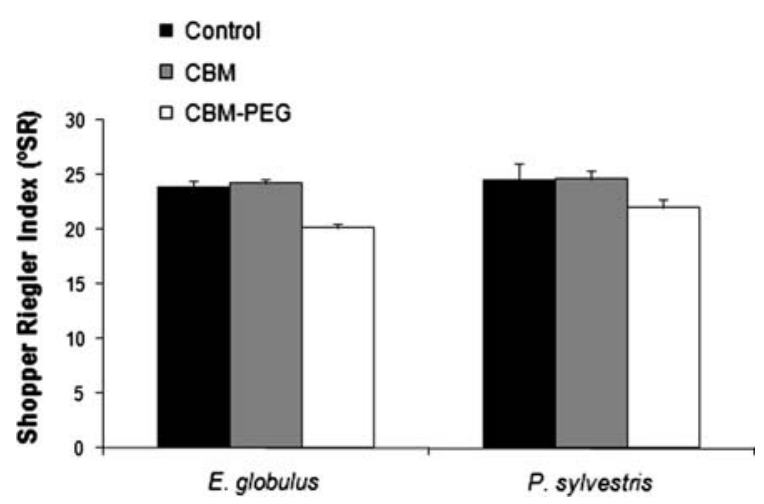

Fig. 4 Shopper-Riegler Index of the E. globulus and $P$. sylvestris fibers treated with CBM, CBM-PEG and untreated. (mean \pm SEM, $n=8$ ) 

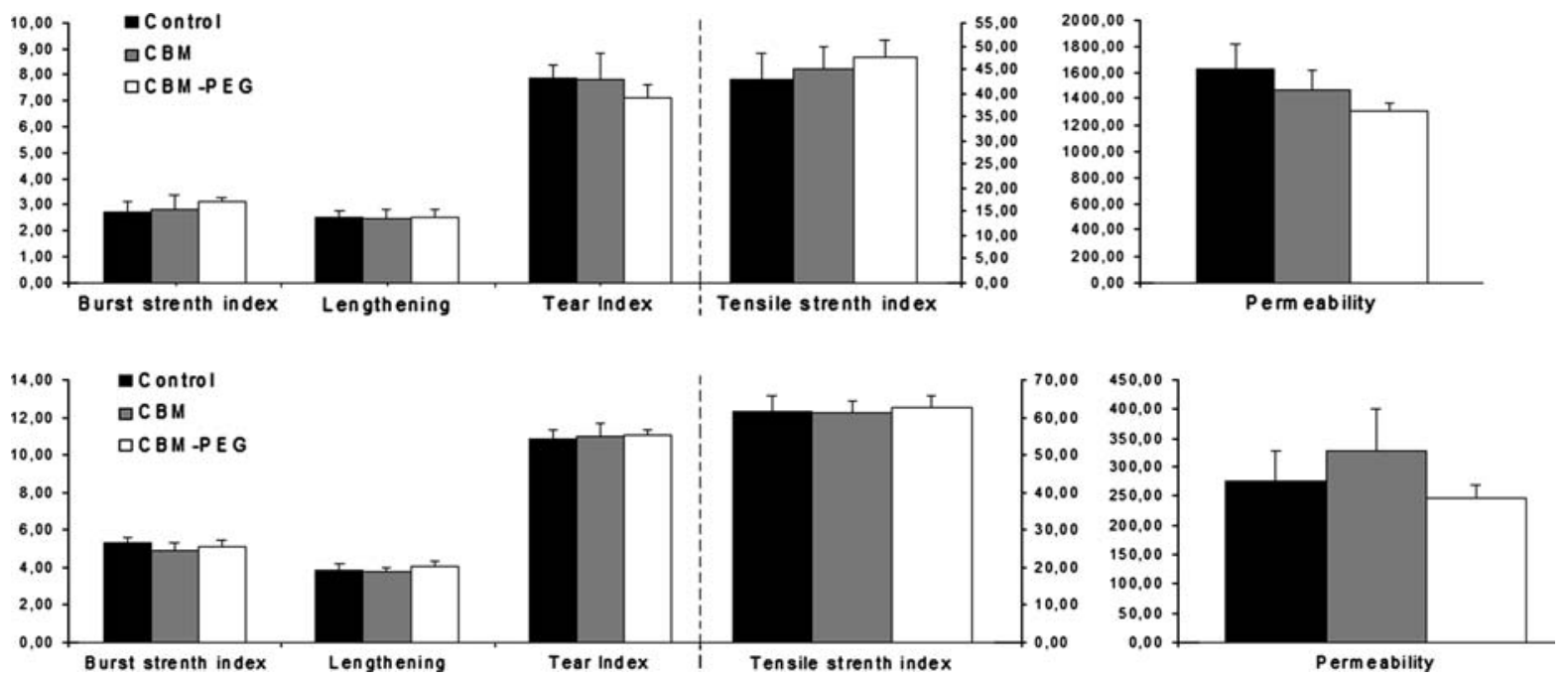

Fig. 5 Physical properties of untreated (control) and CBM and CBM-PEG treated, E. globulus fibres (on top) and $P$. sylvestris fibres (below) (mean $\pm \mathrm{SD})$

pulp for water drainage and is measured by the Shopper-Riegler degree ( $\left.{ }^{\circ} \mathrm{SR}\right)$.

The graph on Fig. 4 shows a significant reduction ( $15.7 \%$ for E. globulus and $10.5 \%$ for P. sylvestris) of the Shopper-Riegler Index ( $\left.{ }^{\circ} \mathrm{SR}\right)$ induced by CBMPEG, and no effect for the pulp treated with CBM, which proves that the CBM needs to be PEGylated to improve the drainability. This result, valid for both pulps, represents an improvement in the pulp drainability comparable to the reported using cellulases. The improved drainability observed may be significant for papermaking, allowing relevant energy savings.

For a suitable industrial application of these compounds, it is necessary also that the physical properties of the handsheets are not negatively modified, and thus the physical properties were analysed.

The graph (Fig. 5) shows that, as a general trend, CBM-PEG improves the drainability and does not affect the paper mechanical properties. These results strongly suggest that the effect of CBM3-PEG is due to the modification of the surface/interfacial properties of the fibres, namely the hydrophilicity, (Data not shown).

\section{Conclusions}

The adsorption of CBM3 to the fibres is reversible. The proteins have shown inter-fibre mobility, suggesting that occasionally the CBM desorbs, although at each moment most of the protein remains adsorbed.

Adsorption of CBMs leads to a substantial coverage of the fibres. Indeed, under the conditions used in this work, a surface coating corresponding to 0.8 and 1.5 layers of protein was found. Such a high surface coating suggests that using CBMs the modification of surface properties may achieved. Indeed, the utilization of CBM-PEG improves the drainability of the E. globulus and P. sylvestris pulps without affecting negatively the paper physical properties. This effect is attributed to the hydration of the surface, due to the high water binding power of PEG.

Acknowledgments This research was supported by Fundação para a Ciência e a Tecnologia under grant POCTI/ $\mathrm{BIO} / 45356 / 2002$.

\section{References}

Abushowski A, McCoy JR, Palczuk NC, Van Es T, Davis FF (1977) Effect of covalent attachment of poly(ethylene glycol) on immunogenicity and circulating life of bovine liver catalase. J Biol Chem 252(11):3582-3586

Bailon P, Berthold W (1998) Polyethylene glycol-conjugated pharmaceutical proteins. Pharm Sci Technol Today 1(8): 352-356. doi:10.1016/S1461-5347(98)00086-8

Fontes CM, Hazlewood GP, Morag E, Hall J, Hirst BH, Gilbert HJ (1995) Evidence for a general role for non catalytic thermostabilizing domains in xylanases from thermophilic bacteria. Biochem J 307:151-158 
Fontes CM, Ponte PI, Reis TC, Soares MC, Gama LT, Dias FM, Ferreira LM (2004) A family 6 carbohydrate-binding module potentiates the efficiency of a recombinant xylanase used to supplement cereal-based diets for poultry. $\mathrm{Br}$ Poult Sci 45(5):648-656. doi:10.1080/0007166040000 6362

Geng X, Li K (2003) Deiking of recycle mixed office paper using two endoglucanases, CelB and CelE, from anaerobic fungus Orpinomyces PC-2. TAPPI J 2:29-32

Jackson LS, Heitmann JA, Joyce TW (1993) Enzymatic modifications of secondary fibers. TAPPI J 76:147-154

Jervis EJ, Haynes CA, Kiburn DG (1997) Surface diffusion of cellulases and their isolated binding domains on cellulose. J Biol Chem 272:24016-24023. doi:10.1074/jbc.272.38. 24016

Kataeva IA, Li X-L, Chen H, Choi S-K, Ljungdahl LG (1999) Cloning and sequence analysis of a new cellulase gene encoding CelK, a major cellulosome component of Clostridium thermocellum: evidence of gene duplication and recombination. J Bacteriol 181:5288-5295

Kataeva IA, Siedel RDIII, LI X-L, Ljungdahl LG (2001) Properties and mutation analysis of the CelK cellulosebinding domain from the Clostridium thermocellum cellulosome. J Bacteriol 183(5):1552-1559. doi:10.1128/JB. 183.5.1552-1559.2001

Kitaoka T, Tanaka H (2001) Novel paper strength additive containing cellulose binding domain of cellulose. J Wood Sci 47:322-324. doi:10.1007/BF00766721

Klyosov AA, Sinitsyn AP (1981) Enzymatic hydrolysis of cellulose. IV. Effect of major physico-chemical and structural features of the substrate. Bioorg Chem 7:18011812

Levy I, Nussinovitch A, Shpigel E, Shoseyov O (2002) Recombinant cellulose crosslinking protein: a novel paper- modification biomaterial. Cellulose 9:91-98. doi: 10.1023/A:1015848701029

Najmudin S, Guerreiro C, Ferreira L, Romão MJ, Fontes CM, Prates JA (2005) Overexpression, purification and crystallization of the two C-terminal domains of the bifunctional cellulose ctCe19D-Cell44A from Clostridium thermocellum. Acta Crystallogr F61:1043-1045
Pala H, Lemos MA, Mota M, Gama FM (2001) Enzymatic upgrade of old paperboard containers. Enzyme Microb Technol 29:274-279. doi:10.1016/S0141-0229(01)00380-5

Pinto R, Moreira S, Mota M, Gama FM (2004) Studies on the cellulose-binding domains adsorption to cellulose. Langmuir 20:1409-1413. doi:10.1021/la035611u

Pinto R, Amaral AL, Carvalho J, Ferreira EC, Mota M, Gama FM (2007) Development of a method using image analysis and CBD-FITC conjugates for the measurement of CBDs adsorbed onto cellulose fibers. Biotechnol Prog 23(6):1492-1497. doi:10.1021/bp070026v

Pinto R, Amaral AL, Ferreira EC, Mota M, Vilanova M, Ruel K, Gama FM (2008) Quantification of the CBD-FITC conjugates surface coating on cellulose fibres. BMC Biotechnol 8:1. doi:10.1186/1472-6750-8-1

Ramos R, Pinto R, Sampaio L, Mota M, Gama FM (2007) Textile depilling: superior finishing using cellulose binding domains with residual enzyme activity. Biocatal Biotransform 25(1):35-42

Senior DJ, Hamilton J (1993) Xylanase treatment for the bleaching of softwood kraft pulps: the effect of chlorine dioxide substitution. TAPPI J 76:200-206

Seo YB, Shin IC, Jeon Y (2000) Enzymatic and mechanical treatment on chemical pulp. TAPPI J 83:1-9

Shoseyov O, Warren RAJ (1997) Cellulose binding domains-a novel fusion technology for efficient, low cost purification and immobilization of recombinant proteins, innovations, No. 7

Shoseyov O, Shani Z, Levy I (2006) Carbohydrate binding modules: biochemical properties and novel applications. Microbiol Mol Biol Rev 70(2):283-295. doi:10.1128/ MMBR.00028-05

Suurnäki A, Kantelinen A, Buchert J, Viikari L (1994) Enzymeaided bleaching of industrial softwood kraft pulps. TAPPI J 77:111-116

Xie H, Gilbert HJ, Charnock SJ, Davies GJ, Williamson MP, Simpson PJ, Rahgothama S, Fontes CM, Dias FM, Ferreira LM, Bolam DN (2001) Clostridium thermocellum Xyn10B carbohydrate-binding module 22-2: the role of conserved amino acids in lingind binding. Biochemistry 40:91679176 